OPEN ACCESS

Edited by: Simone Beretta

San Gerardo Hospital, Italy

Reviewed by

Marco Bacigaluppi,

San Raffaele Scientific Institute

(IRCCS), Italy

Raffaele Ornello,

University of L'Aquila, Italy

*Correspondence:

Guowen Shi

shigw228@126.com

Specialty section:

This article was submitted to

Stroke,

a section of the journal

Frontiers in Neurology

Received: 11 August 2020 Accepted: 01 February 2021

Published: 01 March 2021

Citation:

Pan Y and Shi G (2021) Silver Jubilee of Stroke Thrombolysis With Alteplase:

Evolution of the Therapeutic Window.

Front. Neurol. 12:593887

doi: 10.3389/fneur.2021.593887

\section{Silver Jubilee of Stroke Thrombolysis With Alteplase: Evolution of the Therapeutic Window}

\author{
Yuanmei Pan and Guowen Shi* \\ Ren Ji Hospital, School of Medicine, Shanghai Jiao Tong University, Shanghai, China
}

In 1995, the results of a landmark clinical trial by National Institute of Neurological Disorders and Stroke (NINDS) made a paradigm shift in managing acute cerebral ischemic stroke (AIS) patients at critical care centers. The study demonstrated the efficacy of tissue-type plasminogen activator (tPA), alteplase in improving neurological and functional outcome in AIS patients when administered within $3 \mathrm{~h}$ of stroke onset. After about 12 years of efforts and the results of the ECASS-III trial, it was possible to expand the therapeutic window to $4.5 \mathrm{~h}$, which still represents a major logistic issue, depriving many AIS patients from the benefits of tPA therapy. Constant efforts in this regards are directed toward either speeding up the patient recruitment for IPA therapy or expanding the current tPA window. Efficient protocols to reduce the door-to-needle time and advanced technologies like telestroke services and mobile stroke units are being deployed for early management of AIS patients. Studies have demonstrated benefit of thrombolysis guided by perfusion imaging in AIS patients at up to $9 \mathrm{~h}$ of stroke onset, signifying "tissue window." Several promising pharmacological and non-pharmacological approaches are being explored to mitigate the adverse effects of delayed tPA therapy, thus hoping to further expand the current tPA therapeutic window without compromising safety. With accumulation of scientific data, stroke organizations across the world are amending/updating the clinical recommendations of tPA, the only US-FDA approved drug for managing AIS patients. Alteplase has been a part of our neurocritical care and we intend to celebrate its silver jubilee by dedicating this review article discussing its journey so far and possible future evolution.

Keywords: stroke, thrombolysis (tPA), alteplase, acute cerebral ischemic stroke, neurocritical care

\section{INTRODUCTION}

Acute cerebral stroke is a cerebrovascular disease characterized by an acute compromise of cerebral perfusion or vasculature. It is fundamentally divided into acute intracerebral hemorrhagic stroke (AHS) and acute cerebral ischemic stroke (AIS), with the latter constituting for about $85 \%$ of the total cases (1). Before 1995, both AHS and AIS patients reaching critical care centers were treated and cared alike, with no efforts made to differentiate between the two with respect to their management. However, in 1995, a landmark clinical trial by National Institute of Neurological Disorders and Stroke (NINDS) in managing AIS with Alteplase, a recombinant tissue-type plasminogen activator (tPA), was published (2). The study initiated a paradigm shift in managing AIS patients, thus triggering the need to quickly differentiate between AHS and AIS conditions. 
However, the trial suggested a narrow treatment window, $3 \mathrm{~h}$ of stroke onset, a major logistic issue that remains challenging even today. Treatment beyond this window was shown to be detrimental to patients' health than being of any help. Efforts have been since made to expand this treatment window to also include AIS patients reaching emergency care beyond the $3 \mathrm{~h}$ window under the benefits of tPA therapy. After over 12 years of constant efforts, European Cooperative Acute Stroke III (ECASS III) study was able to expand this treatment window to $4.5 \mathrm{~h}$ (3). About 8 years later, a meta-analysis of five mechanical thrombectomy trials showed that by bridging tPA with intra-arterial thrombectomy, the treatment window can be expanded to $6 \mathrm{~h}$ (4). In 2018, we learnt that a subset of AIS patients with large vessel occlusion were eligible for intraarterial thrombectomy at up to $24 \mathrm{~h}$ of stroke onset (5). Recent studies are suggesting of tissue-window and not the time-window to guide tPA treatment in AIS patients. Further, few potential pharmacological molecules are being studied as conjunctive to tPA therapy to minimize its post-window adverse effects and, thus, possibly increase the therapeutic window. Hence, at the silver jubilee of tPA in managing AIS patients, we are prompted to look into the 25 years of evolution of the tPA therapeutic window, and at its promising future directions, all of which are summarized below.

\section{TISSUE-TYPE PLASMINOGEN ACTIVATOR}

Tissue-type plasminogen activator (tPA) is a serine protease enzyme that functions as an essential catalyst in thrombolysis (Figure 1). Found in endothelial cells, tPA is released in response to aggregation of activated platelets (6) and catalyzes the conversion of plasminogen to plasmin, by cleaving the zymogen plasminogen at its Arg561-Val562 peptide bond, thus aiding in thrombolysis (7). Its activity is eventually terminated by binding with plasminogen activator inhibitor 1 , or neuroserpina neuronal specific inhibitor of tPA, forming an inactive complex, which is removed from the circulation by LDL-receptor-related protein 1 in liver (7). Synthetic version of tPA (ex., Alteplase) can be made in labs through recombinant biotechnology, some of which are modified to amplify their pharmacokinetic and pharmacodynamic properties (ex., Reteplase and Tenecteplase). Alteplase, the synthetic version of normal human tPA, is FDA approved for treating AIS, myocardial infarction with STelevation, acute pulmonary embolism and with central venous access devices (8). The modified tPA reteplase and tenecteplase possess longer half-life, translating into longer duration of action, and are indicated for management of acute pulmonary embolism and acute myocardial infarction, respectively $(9,10)$.

Post-stroke administration of tPA is associated with its own risks, the most devastating of which is hemorrhagic transformation (HT) by thrombolytic and non-thrombolytic actions (11, 12). Thrombolytic activity of tPA facilitates reperfusion, and post-ischemic reperfusion has been shown to degrade basal lamina and disrupt blood brain barrier (BBB) in as early as $10 \mathrm{~min}$ (13). Post stroke, in humans, the extent of $\mathrm{BBB}$ disruption and its permeability may alter in the first $24 \mathrm{~h}$, resulting in an early HT which is different from a late HT that is witnessed after $24 \mathrm{~h}$, where a persistent disruption is witnessed that lasts for weeks (14). Reactive oxygen species (ROS), bloodderived matrix metalloproteinase (MMP)-9 and brain-derived MMP-2 contribute to early HT, while brain-derived MMP-3, MMP-9, and other proteases guide late HT along with active vascular remodeling and neuroinflammation (12). The tPA induced non-thrombolytic mode of HT is facilitated through increasing the activity of MMPs (MMP-2, MMP-3, MMP9) through protease activated receptor-1, lipoprotein receptor protein receptor signaling and degranulation of neutrophils, and of PDGF-CC through PDGF-receptor- $\alpha$ signaling (12).

\section{TWENTY 5 YEARS OF EVOLUTION OF TPA THERAPEUTIC WINDOW}

Over the past 25 years several clinical trials of international importance has been, and are being, conducted (Figure 2 and Table 1). It all started 25 years ago with two interlinked clinical trials by National Institute of Neurological Disorders and Stroke (NINDS), the results of which were reported together (2). Based on the results from two previous dose escalation studies (15), three therapeutic windows, $0-90,91-180$, and $0-180 \mathrm{~min}$ from stroke onset, for tPA administration was assessed in NINDS trials. The neurological assessments at $24 \mathrm{~h}$ of tPA $(0.9 \mathrm{mg} / \mathrm{kg})$ treatment, addressed in the first part of the study, showed no significant improvement compared to placebo. However, the second part of the study demonstrated a long term clinical benefit of tPA treatment in AIS patients, treated within $3 \mathrm{~h}$ of stroke onset, as measured by "global odds ratio for a favorable outcome." The study also reported a significant increase in symptomatic intracerebral hemorrhage $(\mathrm{sICH})$ within $36 \mathrm{~h}$ of tPA treatment (6.4 vs. $0.6 \%$; $p<0.001$ ). The severity of baseline neurological deficit and brain edema were identified as the variables associated with this increased risk of sICH, which was reported later (16). A few concerns were raised over choosing National Institute of Health Stroke Scale (NIHSS) and global composite scale over other more efficient scales and the imbalance in the baseline stroke severity that might potentially favor the tPA group. This resulted in a subsequent independent reanalysis of the NINDS trial data, which refuted all the concerns, thus supporting the use of tPA to treat AIS patients within $3 \mathrm{~h}$ of stroke onset (17).

Within months after publishing of NINDS results, the European Union also published the results of ECASS I study where a higher dose of tPA $(1.1 \mathrm{mg} / \mathrm{kg})$ was administered to AIS patients within $0-6 \mathrm{~h}$ of stroke onset (18). The studied primary outcome measures failed to elicit significant difference between tPA and placebo group, which was attributed to significant number of protocol violations $(\sim 17 \%)$ included in the analysis. Further a significant increase in parenchymal hemorrhages and mortality was reported in tPA treated group compared to placebo-treated patients. Soon, ECASS II was designed and executed with a lower tPA dose $(0.9 \mathrm{mg} / \mathrm{Kg})$ administered to AIS patients at up to $6 \mathrm{~h}$ of stroke onset (19). However, with no significant difference between the assessed primary end point for treatment and placebo group $(p=0.277)$, it was concluded that 

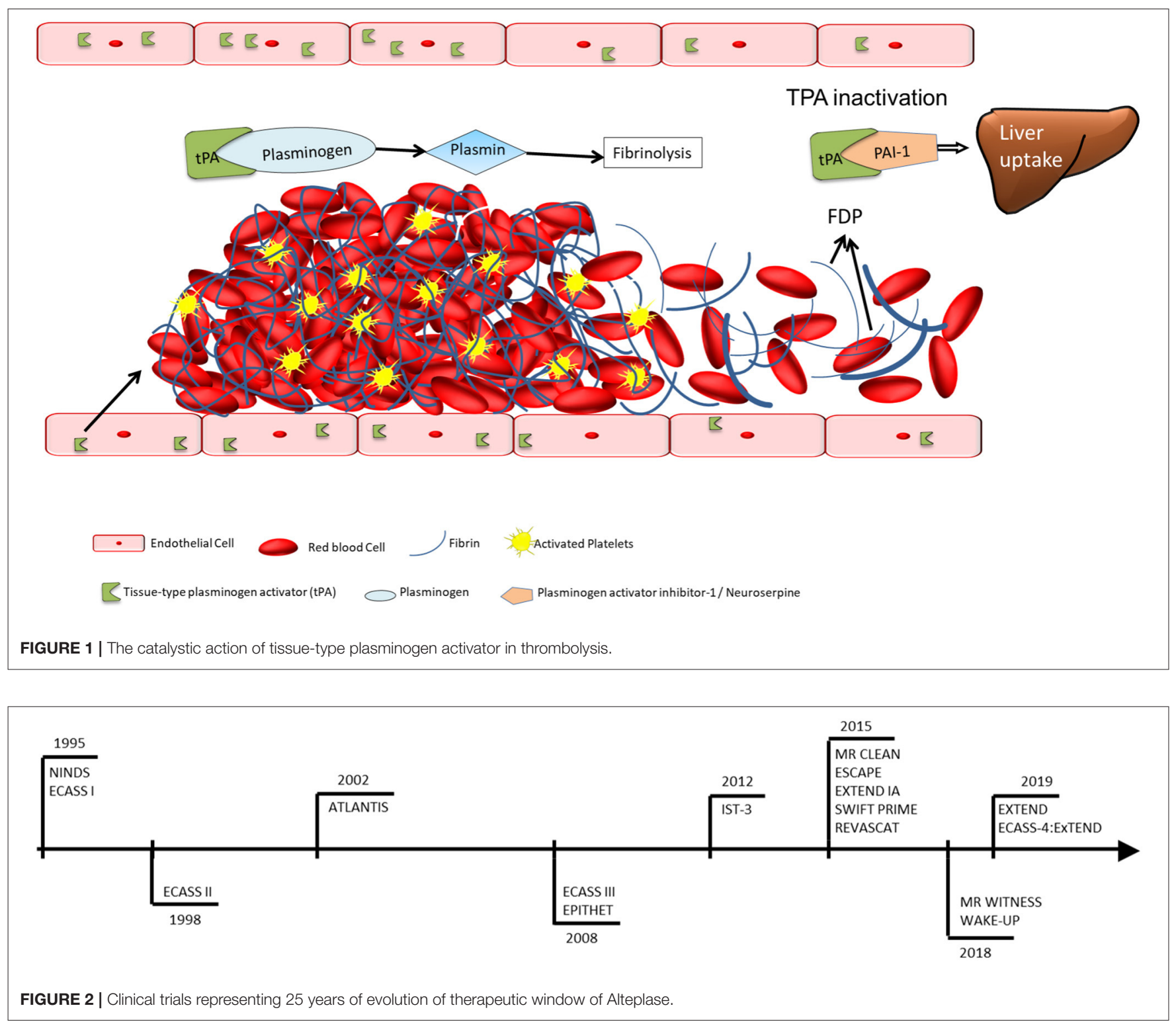

tPA was not beneficial in AIS patients when administered under the study parameters. Another contemporary study was "the alteplase thrombolysis for acute non-interventional therapy in ischemic stroke" (ATLANTIS) study which was initially designed to assess the safety and efficacy of tPA administration in AIS patients within $0-6 \mathrm{~h}$ therapeutic window, and was referred to as part-A (20) (Figure 3). The results found no significant benefits of alteplase administered between 0 and $6 \mathrm{~h}$ after stroke onset, particularly those treated after $3 \mathrm{~h}$. Further, AIS patients receiving tPA at 5-6 h of stroke onset demonstrated a significant increase in sICH. Due to these safety concerns the window was changed to $0-$ $5 \mathrm{~h}$ and continued as ATLANTIS part-B, the results of which was reported according to two subsets of therapeutic window; 0-3 and $3-5 \mathrm{~h}(21,22)$. The patients in $3-5 \mathrm{~h}$ window of tPA treatment showed no better recovery and functional outcome compared to placebo group, added by increased sICH and fatal ICH $(p<$
0.001). However, the results of patients within the $3 \mathrm{~h}$ window of tPA treatment was comparable to NINDS trail results, where they demonstrated a better functional outcome at 90 days, compared to placebo. Hence, the ATLANTIS study recommended the $3 \mathrm{~h}$ therapeutic window for tPA administration in AIS patients.

In 2004 a pooled analysis of the data from NINDS, ECASS, and ATLANTIS trials suggested two interesting conclusions: [1] a greater benefit was observed when tPA administered to AIS patients within $90 \mathrm{~min}$ of stroke onset, upholding the concept of "sooner the better" and [2] a potential benefit beyond $3 \mathrm{~h}$ of tPA administration was also observed, however with some risks (23). This second conclusion prompted the initiation of ECASS III study, at the request from European regulators, to confirm the benefit of the tPA administration beyond $3 \mathrm{~h}$ (3). After assessing data from 821 patients, the results of the study demonstrated a significantly improved clinical outcome in AIS patients when tPA 
TABLE 1 | The results and implications of the key trials of intravenous thrombolysis for ischemic stroke.

\begin{tabular}{|c|c|c|c|c|c|c|}
\hline Study & Hypothesis & $\begin{array}{l}\text { TPA Time } \\
\text { Window }\end{array}$ & Sample size & Main outcome measure & Results & Implications \\
\hline $\begin{array}{l}\text { National Institute of } \\
\text { Neurological } \\
\text { Disorders and } \\
\text { Stroke (NINDS) }\end{array}$ & $\begin{array}{l}\text { Part 1: AIS patients receiving tPA } \\
\text { would demonstrate early ( } 24 \mathrm{~h} \text { ) clinical } \\
\text { improvement, compared to placebo } \\
\text { group } \\
\text { Part 2: AIS patients receiving tPA } \\
\text { would recover with minimal or no } \\
\text { deficit at } 3 \text { months after treatment, } \\
\text { compared to placebo group }\end{array}$ & $0-3 \mathrm{~h}$ & $\begin{array}{l}\text { Part 1: } 291 \\
\text { Part 2: } 333\end{array}$ & $\begin{array}{l}\text { Part 1: } \geq 4 \text { points over baseline } \\
\text { NIHSS score } \\
\text { Part 2: BI MRS GOS NIHSS }\end{array}$ & $\begin{array}{l}\text { Part 1: No significant difference in } \\
\text { neurologic improvement at } 24 \mathrm{~h} \\
\text { between the tPA and placebo group } \\
\text { Part 2: Patients treated with tPA we } \\
30 \% \text { more likely to have no or minimal } \\
\text { disability at } 3 \text { months after treatment, } \\
\text { compared to placebo group } \\
\text { ICH was significantly higher in tPA } \\
\text { group }(p<0.001) \\
\text { Mortality at } 3 \text { months was little lower } \\
\text { in tPA group compared to placebo, } \\
\text { although not significant }\end{array}$ & $\begin{array}{l}\text { Treatment with tPA within } 3 \mathrm{~h} \text { of stroke } \\
\text { onset improved the clinical outcome } \\
\text { at } 3 \text { months in AIS patients, despite } \\
\text { an initial increase in ICH incidence }\end{array}$ \\
\hline ATLANTIS & $\begin{array}{l}\text { To test the efficacy and safety of rt-PA } \\
\text { in patients with acute ischemic stroke } \\
\text { when administered between } 0 \text { and } \\
5 \mathrm{~h} \text { after symptom onset }\end{array}$ & $\begin{array}{l}\text { A: } 0-3 h \\
\text { B: } 3-5 h\end{array}$ & $\begin{array}{l}\text { A: } 61 \\
\text { B: } 613\end{array}$ & $\begin{array}{l}\text { A/B: At } 90 \text { days } \\
\mathrm{NIHSS} \leq 1 \\
\mathrm{BI} \geq 95 \mathrm{MRS} \leq 1 \mathrm{GOS}=1\end{array}$ & $\begin{array}{l}\text { A: Very favorable outcome at } 90 \text { days } \\
\text { B: No significant benefit with } \\
\text { increased ICH }\end{array}$ & $\begin{array}{l}\text { Recommends tPA administration in } \\
<3 \mathrm{~h} \text { of onset of stroke symptoms, } \\
\text { while it doesn't support tPA } \\
\text { administration beyond } 3 \mathrm{~h} \text { window }\end{array}$ \\
\hline ECASS III & $\begin{array}{l}\text { The efficacy of alteplase administered } \\
\text { in patients with acute ischemic stroke } \\
\text { can be safely extended to a time } \\
\text { window of } 3 \text { to } 4.5 \mathrm{~h} \text { after the onset of } \\
\text { stroke symptoms }\end{array}$ & $3-4.5 \mathrm{~h}$ & 821 & $\begin{array}{l}\text { MRS } \leq 1 \\
\text { Composite analysis of: BI, MRS, } \\
\text { GOS, NIHSS }\end{array}$ & $\begin{array}{l}\text { Both primary and secondary outcome } \\
\text { was significantly more in tPA group } \\
\text { compared to placebo group }\end{array}$ & $\begin{array}{l}\text { As compared with placebo, } \\
\text { intravenous alteplase administered } \\
\text { between } 3 \text { and } 4.5 \mathrm{~h} \text { after the onset } \\
\text { of symptoms significantly improved } \\
\text { clinical outcomes in patients with } \\
\text { acute ischemic stroke }\end{array}$ \\
\hline EPITHET & $\begin{array}{l}\text { Primary: Greater attenuation of infarct } \\
\text { growth in patients with an imaging } \\
\text { mismatch who received alteplase } \\
\text { than in those who received placebo } \\
\text { Secondary: Reperfusion, good } \\
\text { neurological outcome, and good } \\
\text { functional outcome would be more } \\
\text { likely in mismatch patients who } \\
\text { received alteplase than in those who } \\
\text { received placebo, Incidence of } \\
\text { symptomatic ICH would be } \\
\text { associated with larger baseline DWI } \\
\text { volumes in patients who received } \\
\text { alteplase }\end{array}$ & $3-6 h$ & 100 & $\begin{array}{l}\text { Primary: infarct growth between } \\
\text { baseline DWI and the day } 90 \text { T2 } \\
\text { lesion in mismatch patients. } \\
\text { Secondary: reperfusion, good } \\
\text { neurological outcome, and good } \\
\text { functional outcome }\end{array}$ & $\begin{array}{l}\text { Reduced infarct growth in alteplase } \\
\text { group, although not significant. } \\
\text { Reperfusion was common with better } \\
\text { neurological outcome and functional } \\
\text { outcome in alteplase group }\end{array}$ & $\begin{array}{l}\text { Alteplase was not significantly } \\
\text { associated with infarct growth, but } \\
\text { significantly associated with increased } \\
\text { reperfusion in patients who had } \\
\text { mismatch }\end{array}$ \\
\hline IST-3 & $\begin{array}{l}0.9 \mathrm{mg} / \mathrm{kg} \text { rt-PA (maximum } 90 \mathrm{mg} \text { ) } \\
\text { given to adult patients of all ages with } \\
\text { acute ischaemic stroke, within } 6 \mathrm{~h} \text { of } \\
\text { symptom onset, increased the } \\
\text { proportion of people who were alive } \\
\text { and independent at } 6 \text { months }\end{array}$ & $0-6 \mathrm{~h}$ & 3,035 & $\mathrm{OHS} \leq 2$ at 6 months & $\begin{array}{l}\text { A similar number of patients were } \\
\text { alive and independent in both the tPA } \\
\text { and control group at } 6 \text { months, with a } \\
\text { significant shift in OHS scores toward } \\
\text { tPA group }\end{array}$ & $\begin{array}{l}\text { Despite the early hazards, alteplase } \\
\text { administration in }<6 \mathrm{~h} \text { of onset of } \\
\text { stroke symptoms improved the } \\
\text { functional outcome, and this benefit } \\
\text { did not diminish in elderly patients } \\
\text { (>80 years of age) }\end{array}$ \\
\hline
\end{tabular}


TABLE 1 | Continued

\begin{tabular}{|c|c|c|c|c|c|c|}
\hline Study & Hypothesis & $\begin{array}{l}\text { TPA Time } \\
\text { Window }\end{array}$ & Sample size & Main outcome measure & Results & Implications \\
\hline MR WITNESS & $\begin{array}{l}\text { A quantitative diffusion-FLAIR } \\
\text { mismatch (qDFM) can be used in } \\
\text { place of time from last known well to } \\
\text { identify stroke patients with } \\
\text { unwitnessed symptom onset who } \\
\text { can safely be treated with } \\
\text { thrombolytic therapy. }\end{array}$ & $\begin{array}{l}4.5-24 \mathrm{~h} \text { since } \\
\text { last } \\
\text { well-known }\end{array}$ & 80 & $\begin{array}{l}\text { Primary: Risk of symptomatic } \\
\text { intracranial hemorrhage (sICH) with } \\
\text { pre-planned stopping rules. } \\
\text { Secondary: symptomatic brain } \\
\text { edema risk, and functional outcomes } \\
\text { of } 90 \text {-day MRS }\end{array}$ & $\begin{array}{l}\text { SICH: } 1 \text { case } \\
\text { Symptomatic edema: } 3 \text { cases } \\
\text { MRS } \leq 1 \text { in } 39 \% \text { cases }\end{array}$ & $\begin{array}{l}\text { Intravenous thrombolysis within } 4.5 \mathrm{~h} \\
\text { of symptom discovery in patients with } \\
\text { unwitnessed stroke selected by } \\
\text { qDFM, who are beyond the } \\
\text { recommended time windows, is safe. }\end{array}$ \\
\hline WAKE UP & $\begin{array}{l}\text { Patients with stroke with an unknown } \\
\text { time of onset and features suggesting } \\
\text { recent cerebral infarction on magnetic } \\
\text { resonance imaging (MRI) would } \\
\text { benefit from thrombolysis with the use } \\
\text { of intravenous alteplase }\end{array}$ & $\begin{array}{l}\text { Unknown time } \\
\text { of onset } \\
{[<4.5 \mathrm{~h} \text { as }} \\
\text { indicated by } \\
\text { ischemic lesion } \\
\text { that was } \\
\text { visible on MRI } \\
\text { diffusion- } \\
\text { weighted } \\
\text { imaging but no } \\
\text { parenchymal } \\
\text { hyperintensity } \\
\text { on FLAIR] }\end{array}$ & 503 & $\begin{array}{l}\text { Primary: MRS } \leq 1 \\
\text { Secondary: Lower ordinal score on } \\
\text { MRS in alteplase grouip than placebo } \\
\text { group }\end{array}$ & $\begin{array}{l}\text { A significantly higher number of } \\
\text { patients in alteplase group } \\
\text { demostrated favorable outcome at } 90 \\
\text { days }\end{array}$ & $\begin{array}{l}\text { In patients with acute stroke with an } \\
\text { unknown time of onset, intravenous } \\
\text { alteplase guided by a mismatch } \\
\text { between diffusion-weighted imaging } \\
\text { and FLAIR in the region of ischemia } \\
\text { resulted in a significantly better } \\
\text { functional outcome and numerically } \\
\text { more intracranial hemorrhages than } \\
\text { placebo at } 90 \text { days }\end{array}$ \\
\hline EXTEND & $\begin{array}{l}\text { Intravenous thrombolysis with } \\
\text { alteplase initiated between } 4.5 \text { and } \\
9.0 \mathrm{~h} \text { after stroke onset or on } \\
\text { awakening with stroke symptoms (for } \\
\text { which the time of onset was not } \\
\text { known) would provide a benefit in } \\
\text { patients who had a small core volume } \\
\text { of cerebral infarction that was } \\
\text { disproportionate to a larger area of } \\
\text { hypoperfusion }\end{array}$ & $\begin{array}{l}4.5-9 \mathrm{~h} \text { after } \\
\text { the onset of } \\
\text { stroke or on } \\
\text { awakening } \\
\text { with stroke }\end{array}$ & 225 & $\mathrm{MRS} \leq 1$ & $\begin{array}{l}\text { A significantly higher number of } \\
\text { patients in alteplase group } \\
\text { demostrated favorable outcome at } 90 \\
\text { days }\end{array}$ & $\begin{array}{l}\text { In AIS patients with salvageable brain } \\
\text { tissue, alteplase treatment within the } \\
\text { specified time results in higher } \\
\text { percentage of patients with no or } \\
\text { minor neurologic symptoms than } \\
\text { palcebo }\end{array}$ \\
\hline ECASS-4-EXTEND & $\begin{array}{l}\text { ischemic stroke patients selected with } \\
\text { significant penumbral mismatch on } \\
\text { magnetic resonance imaging (MRI) at } \\
4.5-9 \mathrm{~h} \text { after onset of stroke will have } \\
\text { improved clinical outcomes when } \\
\text { given intravenous rt-PA (alteplase) } \\
\text { compared to placebo }\end{array}$ & $\begin{array}{l}4.5-9 \mathrm{~h} \text { after } \\
\text { the onset of } \\
\text { stroke or on } \\
\text { awakening } \\
\text { with stroke }\end{array}$ & 111 & $M R S \leq 1$ & $\begin{array}{l}\text { Patients with mismatch showed odds } \\
\text { ratio in favor of treatment benefit of } \\
\text { alteplase at } 90 \text { days }\end{array}$ & $\begin{array}{l}\text { A DWI-FLAIR mismatch in the region } \\
\text { of ischemia as imaging based } \\
\text { surrogate parameter for patient } \\
\text { selection for i.v. rt-PA should be } \\
\text { strongly pursued }\end{array}$ \\
\hline
\end{tabular}




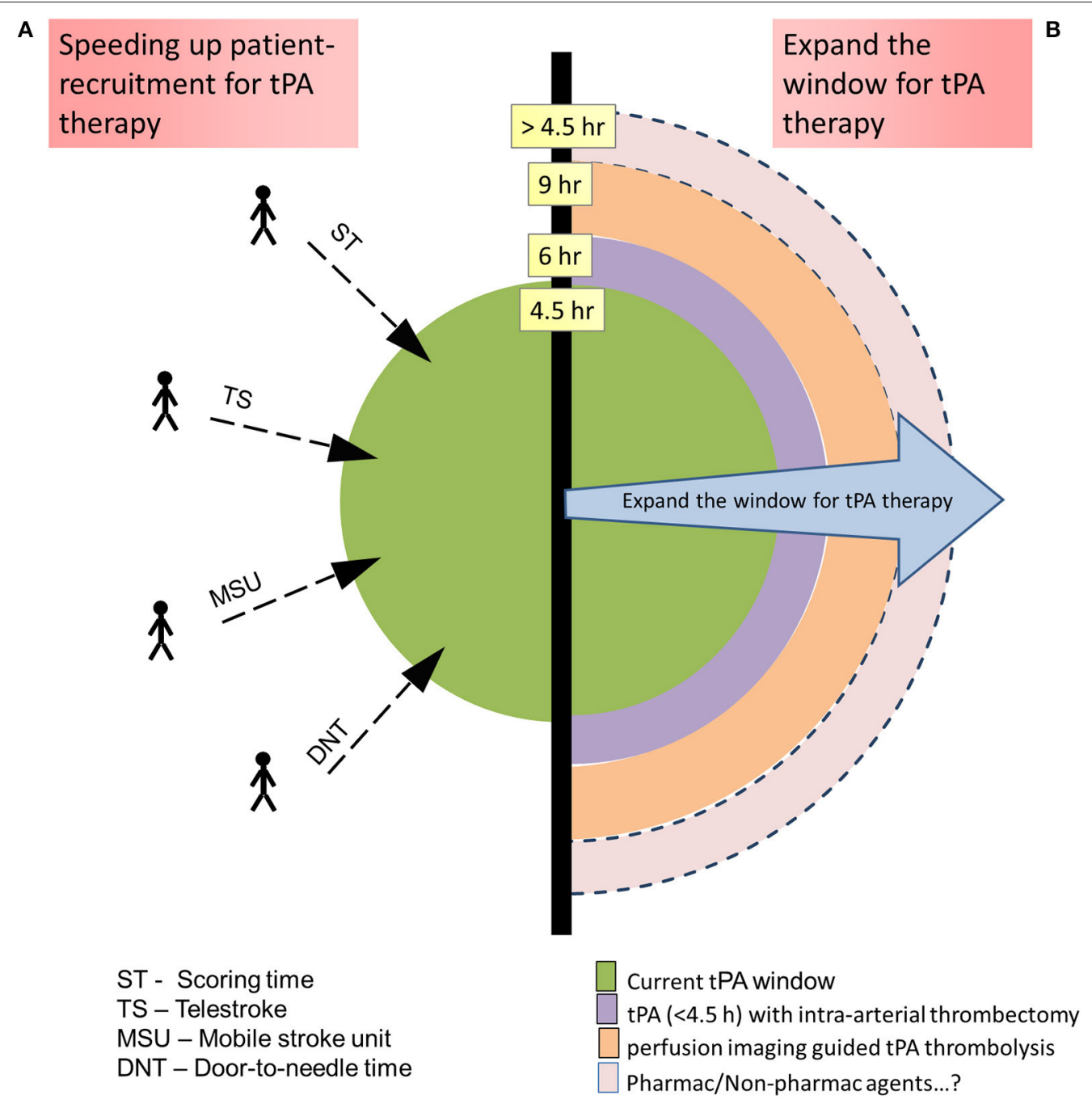

FIGURE 3 | Methods to increase the number of acute ischemic stroke patients' eligibility for tissue-type plasminogen activator (tPA) therapy: (A) By speeding up the patient recruitment so that they fall within the recommended tPA therapeutic window. (B) Expanding the tPA therapeutic window with added technologies/therapies.

was administered between 3 and $4.5 \mathrm{~h}$ of stroke onset. A metaanalysis of these major trials also supported the benefit of tPA when administered between 0 and $4.5 \mathrm{~h}$ of stroke onset in AIS patients (24).

In most of the above studies, elderly patients, aged $>80$ years, were under-represented $(25,26)$, which resulted in regulatory restriction of tPA use in this group of AIS patients. This was addressed in a decade long study, "Third International Stroke Trial" (IST-3), the results of which revealed that the $>80$ year old AIS patients were equally benefited from tPA treatment as in younger patients (27). Further the study assessed a therapeutic window of $6 \mathrm{~h}$ of stroke onset for tPA administration and claimed an improved functional outcome in the recruited patients, despite early hazards. A comprehensive individual patient meta-analysis of data from 6756 AIS patients enrolled in all the above clinical trials was carried out to assess the effect of therapeutic window, age and stroke severity on the outcome of tPA therapy (28). The results confirmed a generalized efficacy of tPA across age and stroke severity spectra with a good functional outcome when delivered within $4.5 \mathrm{~h}$ of stroke onset, although an increased risk of fatal ICH was evident in the early days of treatment.

These studies relied on traditional CT scan to image early infarct signs in AIS patients and on Alberta stroke program early CT (ASPECT) score to decide the risk of hemorrhagic transformation. However, by 1999 considerable number of studies were indicating MRI techniques, particularly the mismatch between Diffusion-weighted imaging (DWI) and Perfusion-weighted imaging (PWI), could identify potentially salvageable brain tissue in a subset of AIS patients who might then benefit from tPA therapy beyond its $3 \mathrm{~h}$ window (Figure 4) (29). This triggered a small phase-2 randomized placebo controlled trial, referred to as "echoplanar imaging thrombolytic evaluation trial” (EPITHET), which targeted AIS patients between 3 and $6 \mathrm{~h}$ post stroke onset (30). The results 


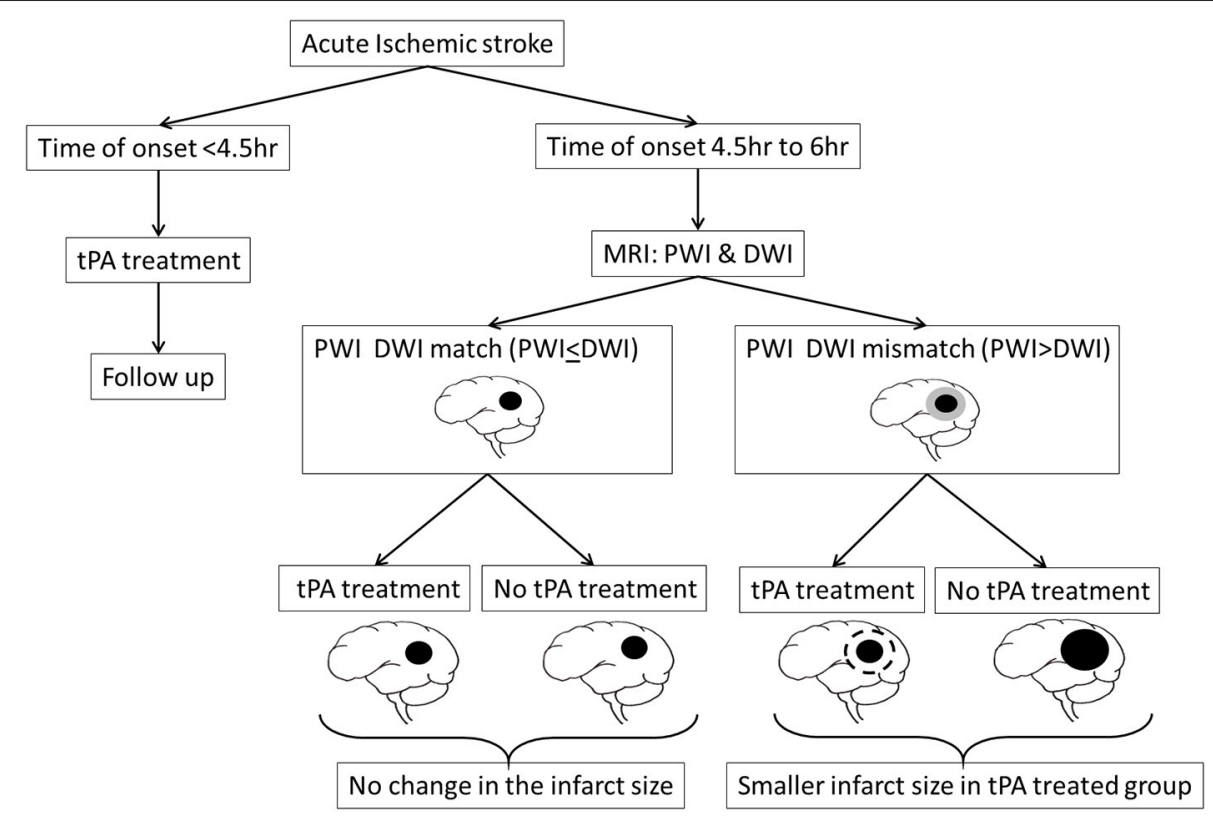

FIGURE 4 | MRI could identify potentially salvageable brain tissue, as indicated by a mismatch between Diffusion-weighted imaging (DWI) and Perfusion-weighted imaging (PWI), in a subset of AIS patients who might then benefit from tPA therapy beyond its $4.5 \mathrm{~h}$ therapeutic window.

indicated that in mismatch patients, tPA could attenuate infarct growth and increase reperfusion, which translated into improved clinical outcomes even when tPA was administered beyond its $3 \mathrm{~h}$ window $(30,31)$. When imaged immediately before and 3-6 h post tPA treatment, MRI was also successful in identifying AIS patients who are likely to clinically respond to early reperfusion treatments (32).

EXTEND and ECASS-4:EXTEND are two other studies which assessed the effectiveness of perfusion imaging guided tPA thrombolysis at up to $9 \mathrm{~h}$ of AIS onset, with contradicting results (33-36). The EXTEND study found excellent functional outcome in perfusion mismatch AIS patients, compared to placebo group, when tPA was administered between 4.5 and $9 \mathrm{~h}$ of stroke onset. However, the ECASS-4:EXTEND failed to elicit any significant benefits of alteplase administered at the same therapeutic window. Considering the modest sample size in each of these trials, a meta-analysis was carried out involving data from EXTEND, ECASS-4:EXTEND and EPITHET trails the results of which implicate that the AIS patients with perfusion mismatch, suggesting of salvageable brain tissue, do demonstrate improved functional outcome even when the tPA was administered beyond its $4.5 \mathrm{~h}$ window, for up to $9 \mathrm{~h}$ of stoke onset (37). Few patients reach the emergency department with unknown time of stroke onset, making them ineligible for tPA therapy on timing alone. MR WITNESS and WAKE-UP are two randomized trials which addressed this issue with the help of MRI-guided thrombolysis $(38,39)$. Both MR WITNESS and WAKE-UP studies concluded that it is safe and effective to administer tPA guided by the diffusion mismatch and perfusion mismatch in AIS patients, respectively, with unknown time of onset, which compels the importance of "tissue window" and not "time window" in AIS management with tPA (40). Based on these results, the 2019 guidelines from American Heart Association/American Stroke Association (AHA/ASA) gave a class IIa recommendation to consider the AIS patients with unclear time of onset or who wake-up with stroke symptoms, in whom MRI show a mismatch between DWI and FLAIR signals, no signs of intracranial hemorrhage or the lesions not larger than $1 / 3$ rd of the territory of the middle cerebral artery, and the NIHSS score of $<25$, for tPA administration within $4.5 \mathrm{~h}$ from the stroke symptom recognition (41). In 2015 five randomized clinical trials (MR CLEAN, ESCAPE, EXTEND IA, SWIFT PRIME, and REVASCAT) were published reporting the efficacy of endovascular thrombectomy in AIS patients with proximal arterial occlusion (42-46). A meta-analysis of these trials revealed that by bridging tPA with intrarticular thrombectomy the treatment window could be expanded up to $6 \mathrm{~h}$ (4). In clinical settings, when eligible, intravenous thrombectomy is often combined with endovascular thrombectomy in a process referred to as bridging-therapy. The efficacy of bridging-therapy over endovascular therapy alone is controversial with few studies showing no added benefit (4750 ), while other studies demonstrating considerable benefits (51-53). Of interest, a recent study reported that bridgingtherapy resulted in improved cognitive function in patients with large cerebral vessel occlusion stroke, at 90 days after index ischemic stroke, compared to endovascular therapy alone (54). This demonstrates that the intravenous tPA administration has an added advantage when combined with mechanical thrombectomy and administered within the specified timeline.

Initially, the NINDS stroke trial group conducted a workshop which concluded to propose a global statistic to test the trial's primary hypothesis and secondary tests of individual outcomes, 
and familiarize the clinical/scientific community with such global approach (55). However, it was not well-received by the community leading to a considerable heterogeneity in the outcome measures across the stroke trials since then (56). Such heterogeneity can be attributed to the availability of several assessment tools, which focuses primarily on either measuring neurological impairment or on the degree of functional independence of the patient. Further, difference in timing of the assessments and data collection in stroke trials also contributes to the observed heterogeneity, all of which makes it extremely difficult to compare between the studies and draw meaningful conclusions from the large number of published stroke trials.

\section{tPA IN CURRENT CLINICAL SETTINGS: HOW THE PAST HAS SHAPED THE PRESENT}

Following NINDS trial results USFDA approved alteplase for treating AIS patients within $3 \mathrm{~h}$ of stroke onset. The drug label portray inclusion and exclusion criteria of NINDS trial, with the following contraindications: current intracranial hemorrhage, subarachnoid hemorrhage, active internal bleeding, intracranial/intraspinal surgery or serious head trauma in the past 3 months, intracranial conditions that may increase risk of bleeding, bleeding diathesis, and current severe uncontrolled hypertension. In Europe, alteplase was approved with more stringent exclusion criteria which also excluded AIS patients with: $>80$ years of age, on anticoagulant therapy, history of stroke and diabetes, and current severe stroke. Later, following ECASS III study results, European Union relaxed the inclusion and exclusion criteria to mirror that of the ECASS III criteria, and the treatment window was extended to $4.5 \mathrm{~h}$. The age and stroke severity was also relaxed based on the results of the meta-analysis of data from 6,756 patients enrolled in major trials (28). The results of the meta-analysis reveal that, despite higher rate of $\mathrm{ICH}$ and mortality as compared to $<80$ years old patients, $>80$ years old patients treated with tPA within $3 \mathrm{~h}$ of onset of stroke symptoms demonstrate a better chance of being independent at 3 months. Further, the analysis also establish a clinical benefit of tPA therapy in AIS patients with severe stroke symptoms and in patients with mild but disabling stroke symptoms, both of which were considered as exclusion criteria previously. This treatment label holds good in most of the countries across the world, except USA and Canada, who follow $3 \mathrm{~h}$ window. However, AHA/ASA and American Academy of Neurology have endorsed this extended time window (57). Further, AHA/ASA has issued statement that additional criteria from ECASS III should not be considered as strict exclusion criteria for tPA therapy in AIS patients (58). Considering the results from perfusion imaging mismatch studies the current AHA/ASA guidelines (2019) has given a class IIa (moderate) recommendation to select patients who wake up with symptoms for alteplase treatment (41). Influenced by DAWN study results, mechanical thrombectomy up to $24 \mathrm{~h}$ of stroke onset has also been given a status of class $1 \mathrm{~A}$ recommendation by AHA/ASA in its 2019 guidelines. The FDA prescribing information (PI) for alteplase was also updated (58) https://www.accessdata. fda.gov/drugsatfda_docs/label/2015/103172s5203lbl.pdf), which now extended the age of the AIS patients to 77 years after which a warning was added. Further, the contraindications like prior stroke within 3 months and seizure at onset are now removed completely from the PI. Further, the warnings on administering tPA to AIS patients with low blood glucose $(<50 \mathrm{mg} / \mathrm{dl})$ level, NIHSS $>22$ or mild stroke are also lifted. History of ICH, which was a contraindication for tPA use in AIS patients initially has been removed now with a warning added for recent ICH. However, current ICH, subarachnoid hemorrhage and severe uncontrolled hypertension remains contraindicated. In this way, along with the tPA therapeutic window, the inclusion criteria of AIS patients for tPA therapy has also evolved over time.

\section{COMPLICATIONS OF ALTEPLASE THERAPY AND ITS MANAGEMENT}

Alteplase administration in AIS patients can induce symptomatic/fatal intracerebral hemorrhage, systemic hemorrhage, and angioedema in about 6,2 , and $5 \%$ of the patients, respectively (59). The risk of hemorrhage increases with age and stroke severity with large areas of ischemic change and leukoaraiosis. Associated conditions like obesity, hyperglycemia, hypertension, cardiac conditions, and use of antiplatelet agents also increases the risk of hemorrhage. A gender bias, with male patients demonstrating increased risk of hemorrhage, is also reported. In addition to regulating the underlying condition, it is recommended to manage hemorrhage with cryoprecipitate or protein complex concentrate, although literature on its benefits are feeble (60). Patients on angiotensin-converting enzyme (ACE) inhibitor are at a higher risk for angioedema, which when involves oropharynx can compromise airway. It is essential to act quickly, typically managed with steroids, antihistamines and intubation if needed. AHA/ASA guidelines recommend the stroke centers to have systems (protocols, personnel, and devices) to manage such complications (41).

\section{EMERGING STRATEGIES AND FUTURE DIRECTIONS OF EVOLUTION}

The evolution of tPA therapy is directed toward ways to increase the number of AIS patients eligible for the therapy either by speeding up the patient recruitment, so that they fall within the recommended therapeutic window, or by expanding the window with added therapies.

\section{Speeding Up Patient-Recruitment for tPA Therapy}

Current guidelines recommend to transport AIS patient directly to comprehensive stroke center when the travel time is $<15 \mathrm{~min}$, than to other hospitals (61). However, this is not always possible, especially in patients living in non-urban areas. To address the issue, telemedicine, a growing field of technology, is being adopted in stroke management programs. Referred to as telestroke, it facilitates audiovisual communication where 
neurologists from a stroke center can guide the physicians at a place with limited access to neurologists, thus enabling a safer and quick management of AIS patients. Studies have determined the technology as safe and effective (62) and thus bags IIa recommendation from AHA/ASA, as the clinical outcomes over long run is not clear yet (63). Considering the importance of time window, few centers implemented mobile stroke units to minimize the tPA window (64). However, this is an expensive venture requiring a fully functional CT scan machine within the ambulance along with a Neurologist, critical care nurse, and CT technician, which makes it impractical at many centers across the globe. Further, the data on the outcome of AIS patients availing the advantage of mobile stroke unit, vs. those not, is limited to conclude the advantage of such system. A delay in door-to-needle time has been associated with poor outcome in AIS patients (65), especially in posterior circulation stroke (PCS) conditions (66). Thus, efforts are made to decrease the door-to-needle time, although the benefits of such efforts are yet to be established $(67,68)$.

An efficient organization of a stroke care system is equally important to ensure short treatment time, toward which several recommendations and guidelines have been established. A recent update on policy statement from American Stroke Association (ASA) has listed the essential framework of the stroke care system composed of eight domains as follows: community education, primordial prevention, primary prevention, emergency medical service (EMS) response, acute stroke treatment, secondary stroke prevention, stroke rehabilitation and continuous quality improvement (61). The first three domains work as preventive strategies. Educating the community is also extremely helpful in quickly identifying a stroke victim and use the EMS, the 4 th domain, to reach the correct hospital in time, eventually contributing in reducing patient's time-to-treatment. EMS providers should be educated and trained well to recognize the stroke symptoms, reduce the on-scene time, prenotify the nearest stroke center, and transport without delay, to make sure that the victim receives the treatment as soon as possible. Certifying the hospitals will be of help to identify the correct hospital, toward which USA has designated 4 levels of hospital certification as follows: comprehensive stroke center, primary stroke center, acute stroke-ready center, and thrombectomycapable stroke center. Once patient arrives at the hospital, the hospital should have parallel processes running to keep the door-to-treatment time as short as possible, toward which the stroke centers are modifying and implementing new patient centered protocols achieving better door-to-needle time (67-69). Establishing mobile stroke units and telemedicine contributes to completing patient assessment, at least in part, before the arrival of patient at the hospital, eventually reducing the door-toneedle time. The last three domains are important in preventing the recurrence of the condition and improving the quality of life of the stroke patients, toward which new models of care with patient-centered-approach are being implemented by the stroke centers.

NIHSS is the most widely used scale to assess the AIS patients. However, Burns JD and team reported a significant variation in scoring time between stroke variants when using
NIHSS, where it took 504 min to score basilar artery occlusion as compared to $83 \mathrm{~min}$ for left middle cerebral artery occlusion (70). This indicates that NIHSS is heavily weighted toward ACS symptoms and not PCS symptoms $(66,71)$, which may explain the increased door-to-needle time noted specifically in PCS conditions in results from Australian stroke unit registry (66), resulting in extended NIHSS scale (72). Recently, NIHSS was reported as not enough to detect cognitive deficits in AIS, demanding the need for improvisation of the concerned section (73). As mentioned above, availability of various assessment scales adds to the heterogeneity in the outcome measures across the stroke trials, demanding the need for a more comprehensive scale that is acceptable across the clinical/scientific community. These conditions suggests a clear need for an improved stroke scoring scale that is both accurate and quick, aiding in accelerated recruitment of right AIS patient for tPA therapy.

\section{Expand the Window for tPA Therapy}

Imaging has significantly expanded the time window of a certain subgroup of AIS patients, the details of which are discussed above. However, although studies have showed the benefit of thrombolysis guided by perfusion imaging in AIS patients up to $9 \mathrm{~h}$ of stroke onset (37), the current guidelines has not recommended it, yet, indicating the need for more proof on the concept. Also, image-guided tPA administration in wake-up AIS patients, for up to $4.5 \mathrm{~h}$ from stroke symptom recognition, has received only moderate recommendation (class IIa), indicating conflicting evidence and/or a divergence of opinion about its efficacy, thus demanding more work in the area. The DWI shows us the ischemic core, which is considered irreversible part of the lesion. However, post treatment (tPA or endovascular thrombectomy) follow-up imaging from few early studies indicates that some of these lesions are reversible if blood flow is restored promptly (74-76), although there is uncertainty about this phenomena. A recent systematic review, assessing the results of such studies, confirmed the existence of such reversible DWI lesions and associated them with good clinical outcome following reperfusion (77). The study also highlights the pitfalls of DWI in defining such lesions early enough, opening the window for improvements in the area which might help in redefining ischemic core in early hours of stroke. Thus, imaging the stroke lesion and its surrounding blood vessels, including pial collateral vessels that significantly preserve the brain tissue in the penumbral region $(78,79)$, using modern imaging techniques is a hot topic of research in stroke management.

Increase in risk-to-benefit ratio over time, limits the tPA therapeutic window in AIS patients. The most common and devastating risk is HT, addressing which can not only expand the tPA treatment window but also can improve its safety profile. Pre-clinical studies have explored several pharmacological and non-pharmacological agents that, when administered with tPA, can stabilize $\mathrm{BBB}$, preserve neurovascular function, attenuate inflammation and offer neuroprotection (80, 81), possibly extending its therapeutic window. Several of such agents have undergone human studies with intriguing, yet unsatisfactory, 
results, the details of which are discussed in recent narratives $(71,82)$. Clinically, a subpopulation of AIS patients who are resistant to tPA has been identified, who fail to respond to tPA treatment even when administered within the approved time-window $(83,84)$. The factors underlying this phenomena is not well-understood, although thrombus location, its size and composition, and the age of the thrombus are known to play a crucial role $(85,86)$. Biologically two types of thrombus can be identified; erythrocyte-rich thrombi and platelet-rich thrombi, and their resistance to tPA thrombolysis has been variedly reported (87-89). In this regards, few pharmacological agents that target other components of the thrombi, von willibard factor (vWF) meshwork or neutrophil extracellular traps (NETs), show promise to overcome tPA resistance (85). During thrombosis, vWF multimers are involved in crosslinking platelets to fibrin, and vWF lysis can thus be promising in platelet-rich thrombi. In experimental stroke models, N-Acetylcysteine, a mucolytic drug, and ADAMTS13, a vWF cleaving enzyme, have shown to effectively dissolve tPA resistant thrombi and reduce cerebral infarct size (90, 91). During thrombosis, neutrophils stabilize the thrombus structure by releasing DNA filaments composed of histones and cytoplasmic granule proteins, referred to as NETs, which are shown to impair tPA-induced thrombolysis (92). Deoxyribonuclease (DNAse) enzyme can counteract the NETs activity and has shown protective effect in experimental stroke model (93). Further, under in vitro condition, DNAse has shown to augment the tPA mediated thrombolysis and thus is of clinical interest $(92,94)$. Clearly much needs to be achieved before clinical translation of these additive therapies, which when done are promising to add a significant time to the current tPA therapeutic window.

\section{Modified Tissue Plasminogen Activators}

The limitations of alteplase, such as increased bleeding risk, potential neurotoxicity, and short half-life (about $5 \mathrm{~min})(8,11-$ $13,95)$, have lead to the development of new thrombolytic agents over the past 25 years, that includes reteplase, tenecteplase, desmoteplase, monteplase, pamiteplase, lanoteplase, and alfimeprase $(96,97)$. Of these, tenecteplase and desmoteplase demonstrate longer plasma half-life, improved fibrin specificity, better resistance to plasminogen activator inhibitor and lower neurotoxicity, and show promise in treating AIS (98). At $3-6 \mathrm{~h}$ of stroke onset, $0.1 \mathrm{mg} / \mathrm{kg}$ of tenecteplase was superior to $0.9 \mathrm{mg} / \mathrm{kg}$ of alteplase in achieving better reperfusion, recancanalizaion with improved NIHSS score in AIS patients at $24 \mathrm{~h}$ (99). Importantly, tenecteplase allowed the expansion of the treatment window to $6 \mathrm{~h}$ with better efficacy than alteplase at both $24 \mathrm{~h}$ and 90 days, as confirmed in phase 2 and phase 3 trials $(100,101)$. Based on the results of these studies, current clinical guidelines suggest intravenous tenecteplase, at a dose of 0.25 or $0.4 \mathrm{mg} / \mathrm{kg}$, as a second-tier option in treating large vessel occlusions (101). Desmoteplase is a recombinant version of DSPA $\alpha 1$, a plasminogen activator isolated from the saliva of the vampire bat (102). Due to its high fibrin specificity and low neurotoxicity, desmoteplase is a promising thrombolytic agent currently under trials for treating AIS. Meta-analsysis of these clinical trials conclude that desmoteplase is associated with a favorable reperfusion and acceptable safety when administered after $3 \mathrm{~h}$ and up to $9 \mathrm{~h}$ of onset of stroke symptoms $(103,104)$. More trials are underway to assess its true efficacy in AIS patients.

\section{CONCLUSION}

Time is the mantra of brain, and is of prime consideration when it comes to managing stroke. Any patient with AIS presenting to hospital within $4.5 \mathrm{~h}$ of symptom onset should be promptly treated with intravenous tPA, unless otherwise contraindicated. To truly maximize the benefit of tPA therapy, one should reduce the onset of tPA administration to the earliest possible time. Studies have demonstrated that every minute saved in achieving reperfusion translates into 1.8 days (mean) of "disability adjusted life years" in AIS patients, while loss of every $20 \mathrm{~min}$ increased the "number needed to treat" to achieve excellent outcome by 1 (95). Further, a significant reduction in hospital stay, in-hospital mortality and other adverse effects of tPA administration was reported with a 15 min reduction in door-to-needle time (105). Systems/protocols to minimize the door-to-needle time to the shortest possible period must be implemented in all stroke centers, without compromising safety. It is recommended to train critical care physicians on recognition of stroke symptoms and stroke screening tools which may reduce the door-to-needle time (106). It is believed that the number of AIS patients receiving tPA therapy remains much lower than what is achievable. In this regard, it is recommended to educate public on early detection of stroke symptoms that may facilitate early transportation of such stroke patients to critical care centers. Systems like mobile stroke unit and telestroke services hold great promise to include more AIS patients under the tPA umbrella. "Tissue window" should be considered when a patient reaches beyond the recommended 4.5 time window, which may qualify many perfusion mismatch patients to tPA therapy. Improving the safety profile of tPA therapy with combination therapies are further warranted, which may also contribute to improved clinical outcomes. Further, such therapies may also extend the current tPA therapeutic window, qualifying many more AIS patients for tPA therapy who are otherwise deemed ineligible currently.

\section{AUTHOR CONTRIBUTIONS}

YP and GS: substantial contributions to the conception, design of the work and acquisition of data for the work, drafting the work or revising it critically for important intellectual content, final approval of the version to be published and agreement to be accountable for all aspects of the work in ensuring that questions related to the accuracy or integrity of any part of the work are appropriately investigated and resolved. 


\section{REFERENCES}

1. Mozaffarian D, Benjamin EJ, Go AS, Arnett DK, Blaha MJ, Cushman $\mathrm{M}$, et al. Heart disease and stroke statistics-2016 update: a report from the american heart association. Circulation. (2016) 133:e38-360. doi: 10.1161/CIR.0000000000000350

2. The National Institute of Neurological Disorders and Stroke rt-PA Stroke Study Group. Tissue plasminogen activator for acute ischemic stroke. N Engl J Med. (1995) 333:1581-7. doi: 10.1056/NEJM199512143332401

3. Hacke W, Kaste M, Bluhmki E, Brozman M, Davalos A, Guidetti D, et al. Thrombolysis with alteplase 3 to 4.5 hours after acute ischemic stroke. $N$ Engl J Med. (2008) 359:1317-29. doi: 10.1056/NEJMoa0804656

4. Goyal M, Menon BK, van Zwam WH, Dippel DW, Mitchell PJ, Demchuk $\mathrm{AM}$, et al. Endovascular thrombectomy after large-vessel ischaemic stroke: a meta-analysis of individual patient data from five randomised trials. Lancet. (2016) 387:1723-31. doi: 10.1016/S0140-6736(16)00163-X

5. Powers WJ, Rabinstein AA, Ackerson T, Adeoye OM, Bambakidis NC, Becker K, et al. 2018 guidelines for the early management of patients with acute ischemic stroke: a guideline for healthcare professionals from the american heart association/american stroke association. Stroke. (2018) 49:e46-e110. doi: 10.1016/j.jvs.2018.04.007

6. Stricker RB, Wong D, Shiu DT, Reyes PT, Shuman AM. Activation of plasminogen by tissue plasminogen activator on normal and thrombasthenic platelets: effects on surface proteins and platelet aggregation. Blood. (1986) 68:275-80. doi: 10.1182/blood.V68.1.275.bloodjournal681275

7. Jilani TN, Siddiqui HA. Tissue plasminogen activator. In: StatPearls. FL: Treasure Island (2020).

8. Reed M, Kerndt CC, Nicolas D. Alteplase. In: StatPearls. FL: Treasure Island (2020).

9. Wang W, Zhao X, Ren Y, Qiao P. Therapeutic effect evaluation of reteplase on acute pulmonary embolism. Pakistan J Pharmaceut Sci. (2018) 31:899905.

10. Saran RK, Sethi R, Nagori M. Tenecteplase-the best among the equals. Indian Heart J. (2009) 61:454-8.

11. Wang W, Li M, Chen Q, Wang J. Hemorrhagic transformation after tissue plasminogen activator reperfusion therapy for ischemic stroke: mechanisms, models, and biomarkers. Mol Neurobiol. (2015) 52:1572-9. doi: $10.1007 /$ s12035-014-8952-x

12. Jickling GC, Liu D, Stamova B, Ander BP, Zhan X, Lu A, et al. Hemorrhagic transformation after ischemic stroke in animals and humans. J Cereb Blood Flow Metabol. (2014) 34:185-99. doi: 10.1038/jcbfm.2013.203

13. Wang CX, Shuaib A. Critical role of microvasculature basal lamina in ischemic brain injury. Progr Neurobiol. (2007) 83:140-8. doi: 10.1016/j.pneurobio.2007.07.006

14. Sandoval KE, Witt AK. Blood-brain barrier tight junction permeability and ischemic stroke. Neurobiol Dis. (2008) 32:200-19. doi: 10.1016/j.nbd.2008.08.005

15. Brott TG, Haley EC, Levy DE Jr, Barsan W, Broderick J, Sheppard GL, et al. Urgent therapy for stroke. Part I. Pilot study of tissue plasminogen activator administered within 90 minutes. Stroke. (1992) 23:632-40. doi: 10.1161/01.STR.23.5.632

16. The NINDS t-PA Stroke Study Group. Intracerebral hemorrhage after intravenous t-PA therapy for ischemic stroke. The NINDS t-PA Stroke Study Group. Stroke. (1997) 28:2109-18. doi: 10.1161/01.STR.28.11.2109

17. Ingall TJ, O’Fallon WM, Asplund K, Goldfrank LR, Hertzberg VS, Louis TA, et al. Findings from the reanalysis of the NINDS tissue plasminogen activator for acute ischemic stroke treatment trial. Stroke. (2004) 35:2418-24. doi: 10.1161/01.STR.0000140891.70547.56

18. Hacke W, Kaste M, Fieschi C, Toni DE, Lesaffre, von Kummer R, et al. Intravenous thrombolysis with recombinant tissue plasminogen activator for acute hemispheric stroke. The European Cooperative Acute Stroke Study (ECASS). JAMA. (1995) 274:1017-25. doi: 10.1001/jama.274.13.1017

19. Hacke W, Kaste M, Fieschi C, von Kummer R, Davalos A, Meier D, et al. Randomised double-blind placebo-controlled trial of thrombolytic therapy with intravenous alteplase in acute ischaemic stroke (ECASS II). Second European-Australasian Acute Stroke Study Investigators. Lancet. (1998) 352:1245-51. doi: 10.1016/S0140-6736(98)08020-9
20. Clark WM, Albers GW, Madden KP, Hamilton S. The rtPA (alteplase) 0- to 6-hour acute stroke trial, part A (A0276g): results of a double-blind, placebocontrolled, multicenter study. Thromblytic therapy in acute ischemic stroke study investigators. Stroke. (2000) 31:811-6. doi: 10.1161/01.STR.31.4.811

21. Albers GW, Clark WM, Madden KP, Hamilton AS. ATLANTIS trial: results for patients treated within 3 hours of stroke onset. Alteplase thrombolysis for acute noninterventional therapy in ischemic stroke. Stroke. (2002) 33:493-5. doi: 10.1161/hs0202.102599

22. Clark WM, Wissman S, Albers GW, Jhamandas JH, Madden KP, Hamilton S. Recombinant tissue-type plasminogen activator (Alteplase) for ischemic stroke 3 to 5 hours after symptom onset. The ATLANTIS Study: a randomized controlled trial. Alteplase thrombolysis for acute noninterventional therapy in ischemic stroke. JAMA. (1999) 282:2019-26. doi: 10.1001/jama.282.21.2019

23. Hacke W, Donnan G, Fieschi C, Kaste M, von Kummer R, Broderick JP, et al. Association of outcome with early stroke treatment: pooled analysis of ATLANTIS. ECASS, and NINDS rt-PA stroke trials. Lancet. (2004) 363:76874. doi: 10.1016/S0140-6736(04)15692-4

24. Lees KR, Bluhmki E, von Kummer R, Brott TG, Toni D, Grotta JC, et al. Time to treatment with intravenous alteplase and outcome in stroke: an updated pooled analysis of ECASS. ATLANTIS, NINDS, EPITHET trials. Lancet. (2010) 375:1695-703. doi: 10.1016/S0140-6736(10)60491-6

25. Sanossian NB. Ovbiagele: Prevention and management of stroke in very elderly patients. Lancet Neurol. (2009) 8:1031-41. doi: 10.1016/S1474-4422(09)70259-5

26. Wardlaw JM, Murray V, Berge E, Del Zoppo JG. Thrombolysis for acute ischaemic stroke. Cochrane Database Systemat Rev. (2009) 4:CD000213. doi: 10.1002/14651858.CD000213.pub2

27. Sandercock P, Wardlaw JM, Lindley RI, Dennis M, Cohen G, Murray G, et al. The benefits and harms of intravenous thrombolysis with recombinant tissue plasminogen activator within $6 \mathrm{~h}$ of acute ischaemic stroke (the third international stroke trial [IST-3]): a randomised controlled trial. Lancet. (2012) 379:2352-63. doi: 10.1016/S0140-6736(12)60768-5

28. Emberson J, Lees KR, Lyden P, Blackwell L, Albers G, Bluhmki E, et al. Effect of treatment delay, age, and stroke severity on the effects of intravenous thrombolysis with alteplase for acute ischaemic stroke: a meta-analysis of individual patient data from randomised trials. Lancet. (2014) 384:1929-35. doi: 10.1016/S0140-6736(14)60584-5

29. Albers GW. Expanding the window for thrombolytic therapy in acute stroke. The potential role of acute MRI for patient selection. Stroke. (1999) 30:22307. doi: 10.1161/01.STR.30.10.2230

30. Davis SM, Donnan GA, Parsons MW, Levi C, Butcher KS, Peeters A, et al. Effects of alteplase beyond $3 \mathrm{~h}$ after stroke in the echoplanar imaging thrombolytic evaluation trial (EPITHET): a placebo-controlled randomised trial. Lancet Neurol. (2008) 7:299-309. doi: 10.1016/S1474-4422(08)70044-9

31. Nagakane Y, Christensen S, Brekenfeld C, Ma H, Churilov L, Parsons $\mathrm{MW}$, et al. EPITHET: positive result after reanalysis using baseline diffusion-weighted imaging/perfusion-weighted imaging co-registration. Stroke. (2011) 42:59-64. doi: 10.1161/STROKEAHA.110.580464

32. Albers GW, Thijs VN, Wechsler L, Kemp S, Schlaug G, Skalabrin E, et al. Magnetic resonance imaging profiles predict clinical response to early reperfusion: the diffusion and perfusion imaging evaluation for understanding stroke evolution (DEFUSE) study. Annals Neurol. (2006) 60:508-17. doi: 10.1002/ana.20976

33. Ma H, Parsons MW, Christensen S, Campbell BC, Churilov L, Connelly A, et al. A multicentre, randomized, double-blinded, placebo-controlled Phase III study to investigate EXtending the time for Thrombolysis in Emergency Neurological Deficits (EXTEND). Int J Stroke. (2012) 7:74-80. doi: 10.1111/j.1747-4949.2011.00730.x

34. Ma H, Campbell BCV, Parsons MW, Churilov L, Levi CR, Hsu $\mathrm{C}$, et al. Thrombolysis guided by perfusion imaging up to 9 hours after onset of stroke. N Engl J Med. (2019) 380:1795-803. doi: 10.1016/j.jemermed.2019.07.005

35. Amiri H, Bluhmki E, Bendszus M, Eschenfelder CC, Donnan GA, Leys D, et al. European cooperative acute stroke study-4: extending the time for thrombolysis in emergency neurological deficits ECASS-4: ExTEND. Int J Stroke. (2016) 11:260-7. doi: 10.1177/1747493015620805 
36. Ringleb P, Bendszus M, Bluhmki E, Donnan G, Eschenfelder C, Fatar M, et al. Extending the time window for intravenous thrombolysis in acute ischemic stroke using magnetic resonance imaging-based patient selection. Int J Stroke. (2019) 14:483-90. doi: 10.1177/1747493019840938

37. Campbell BCV, Ma H, Ringleb PA, Parsons MW, Churilov L, Bendszus M, et al. Extending thrombolysis to $4.5-9 \mathrm{~h}$ and wake-up stroke using perfusion imaging: a systematic review and meta-analysis of individual patient data. Lancet. (2019) 394:139-47. doi: 10.1016/S0140-6736(19)31053-0

38. Schwamm LH, Wu O, Song SS, Latour LL, Ford AL, Hsia AW, et al. Intravenous thrombolysis in unwitnessed stroke onset: MR WITNESS trial results. Annals Neurol. (2018) 83:980-93. doi: 10.1002/ana.25235

39. Thomalla G, Simonsen CZ, Boutitie F, Andersen G, Berthezene Y, Cheng B, et al. MRI-guided thrombolysis for stroke with unknown time of onset. $N$ Engl J Med. (2018) 379:611-22. doi: 10.1056/NEJMoa1804355

40. Wang D, Wang Y. Tissue window, not the time window, will guide acute stroke treatment. Stroke Vascular Neurol. (2019) 4:1-2. doi: 10.1136/svn-2018-000211

41. Powers WJ, Rabinstein AA, Ackerson T, Adeoye OM, Bambakidis NC, Becker $\mathrm{K}$, et al. Guidelines for the early management of patients with acute ischemic stroke: 2019 update to the 2018 guidelines for the early management of acute ischemic stroke: a guideline for healthcare professionals from the American Heart Association/American Stroke Association. Stroke. (2019) 50:e344-418. doi: 10.1161/STR.0000000000000211

42. Berkhemer OA, Fransen PS, Beumer D LA. van den Berg, Lingsma HF, Yoo $\mathrm{AJ}$, et al. A randomized trial of intraarterial treatment for acute ischemic stroke. N Engl J Med. (2015) 372:11-20. doi: 10.1056/NEJMoa1411587

43. Goyal M, Demchuk AM, Menon BK, Eesa M, Rempel JL, Thornton J, et al. Randomized assessment of rapid endovascular treatment of ischemic stroke. N Engl J Med. (2015) 372:1019-30. doi: 10.1056/NEJMoa1414905

44. Campbell BC, Mitchell PJ, Kleinig TJ, Dewey HM, Churilov L, Yassi N, et al. Endovascular therapy for ischemic stroke with perfusion-imaging selection. N Engl J Med. (2015) 372:1009-18. doi: 10.1056/NEJMoa1414792

45. Saver JL, Goyal M, Bonafe A, Diener HC, Levy EI, Pereira VM, et al. Stentretriever thrombectomy after intravenous t-PA vs. t-PA alone in stroke. $N$ Engl J Med. (2015) 372:2285-95. doi: 10.1056/NEJMoa1415061

46. Jovin TG, Chamorro A, Cobo E, de Miquel MA, Molina CA, Rovira A, et al. Thrombectomy within 8 hours after symptom onset in ischemic stroke. $N$ Engl J Med. (2015) 372: 2296-306. doi: 10.1056/NEJMoa1503780

47. Choi JH, Im SH, Lee KJ, Koo JS, Kim BS, Shin SY. Comparison of outcomes after mechanical thrombectomy alone or combined with intravenous thrombolysis and mechanical thrombectomy for patients with acute ischemic stroke due to large vessel occlusion. World Neurosurg. (2018) 114:e165-72. doi: 10.1016/j.wneu.2018.02.126

48. Bellwald S, Weber R, Dobrocky T, Nordmeyer H, Jung S, Hadisurya J, et al. Direct mechanical intervention versus bridging therapy in stroke patients eligible for intravenous thrombolysis. Stroke. (2017) 48:3282-8. doi: 10.1161/STROKEAHA.117.018459

49. Broeg-Morvay A, Mordasini P, Bernasconi C, Bühlmann M, Pult F, Arnold $M$, et al. Direct mechanical intervention versus combined intravenous and mechanical intervention in large artery anterior circulation stroke. Stroke. (2016) 47:1037-44. doi: 10.1161/STROKEAHA.115.011134

50. Kaesmacher J, Mordasini P, Arnold M, López-Cancio E, Cerdá N, BoeckhBehrens $\mathrm{T}$, et al. Direct mechanical thrombectomy in tPA-ineligible and -eligible patients versus the bridging approach: a meta-analysis. $J$ NeuroIntervent Surg. (2019) 11:20-7. doi: 10.1136/neurintsurg-2018-013834

51. Mazighi M, Meseguer E, Labreuche J P. Amarenco: bridging therapy in acute ischemic stroke. Stroke. (2012) 43:1302-8. doi: 10.1161/STROKEAHA.111.635029

52. Katsanos AH, Tsivgoulis G. Is intravenous thrombolysis still necessary in patients who undergo mechanical thrombectomy? Curr Opin Neurol. (2019) 32:3-12. doi: 10.1097/WCO.0000000000000633

53. Pan X, Liu G, Wu B, Liu X, Fang Y. Comparative efficacy and safety of bridging strategies with direct mechanical thrombectomy in large vessel occlusion: a systematic review and meta-analysis. Medicine. (2019) 98:e14956. doi: 10.1097/MD.0000000000014956

54. Ettelt P, Maier IL, Schnieder M, Bähr M, Behme D, Psychogios M-N, et al. Bridging therapy is associated with improved cognitive function after large vessel occlusion stroke - an analysis of the German Stroke Registry. Neurol Res Pract. (2020) 2:29. doi: 10.1186/s42466-020-00079-9

55. Tilley BC, Marler J, Geller NL, Lu M, Legler J, Brott T, et al. Use of a global test for multiple outcomes in stroke trials with application to the national institute of neurological disorders and stroke t-PA stroke trial. Stroke. (1996) 27:2136-42. doi: 10.1161/01.STR.27.11.2136

56. Pistoia F, Sacco S, Ornello R, Degan D, Tiseo CA. Composite scores and other outcome measures in stroke trials. Front Neurol Neurosci. (2016) 39:60-70. doi: $10.1159 / 000445413$

57. Del Zoppo GJ, Saver JL, Jauch EC, Adams HP. Expansion of the time window for treatment of acute ischemic stroke with intravenous tissue plasminogen activator: a science advisory from the American Heart Association/American Stroke Association. Stroke. (2009) 40:2945-8. doi: 10.1161/STROKEAHA.109.192535

58. Demaerschalk BM, Kleindorfer DO, Adeoye OM, Demchuk AM, Fugate JE, Grotta JC, et al. Scientific rationale for the inclusion and exclusion criteria for intravenous alteplase in acute ischemic stroke: a statement for healthcare professionals from the American Heart Association/American Stroke Association. Stroke. (2016) 47:581-641. doi: 10.1161/STR.0000000000000086

59. Miller DJ, Simpson JR, Silver B. Safety of thrombolysis in acute ischemic stroke: a review of complications, risk factors, newer technologies. Neurohospitalist. (2011) 1:138-47. doi: 10.1177/1941875211408731

60. Yaghi S, Willey JZ, Cucchiara B, Goldstein JN, Gonzales NR, Khatri P, et al. Treatment and outcome of hemorrhagic transformation after intravenous alteplase in acute ischemic stroke: a scientific statement for healthcare professionals from the American Heart Association/American Stroke Association. Stroke. (2017) 48:e343-61. doi: 10.1161/STR.0000000000000152

61. Adeoye O, Nystrom KV, Yavagal DR, Luciano J, Nogueira RG, Zorowitz RD, et al. Recommendations for the establishment of stroke systems of care: a 2019 update. Stroke. (2019) 50:e187-210. doi: 10.1161/STR.0000000000000173

62. Kepplinger J, Barlinn K, Deckert S, Scheibe M, Bodechtel U, Schmitt J. Safety and efficacy of thrombolysis in telestroke: a systematic review and meta-analysis. Neurology. (2016) 87:1344-51. doi: 10.1212/WNL.0000000000003148

63. Zhang D, Shi L, Ido MS, Green DE, Li Y, Su D, et al. Impact of participation in a telestroke network on clinical outcomes. Circulat Cardiovascul Quality Outcomes. (2019) 12:e005147. doi: 10.1161/CIRCOUTCOMES.118.005147

64. Calderon VJ, Kasturiarachi BM, Lin E, Bansal V, Zaidat OO. Review of the mobile stroke unit experience worldwide. Int Neurol. (2018) 7:347-58. doi: 10.1159/000487334

65. Man S, Xian Y, Holmes DN, Matsouaka RA, Saver JL, Smith EE, et al. Association between thrombolytic door-to-needle time and 1-year mortality and readmission in patients with acute ischemic stroke. JAMA. (2020) 323:2170-84. doi: 10.1001/jama.2020.5697

66. Sommer P, Seyfang L, Posekany A, Ferrari J, Lang W, Fertl E, et al. Prehospital and intra-hospital time delays in posterior circulation stroke: results from the Austrian Stroke Unit Registry. J Neurol. (2017) 264:131-8. doi: $10.1007 / \mathrm{s} 00415-016-8330-x$

67. Tong X, Wiltz JL, George MG, Odom EC, Coleman King SM, Chang T, et al. A decade of improvement in door-to-needle time among acute ischemic stroke patients, 2008 to 2017. Circulat Cardiovascul Quality Outcomes. (2018) 11:e004981. doi: 10.1161/CIRCOUTCOMES.118.004981

68. Jung S, Rosini JM, Nomura JT, Caplan RJ, Raser-Schramm J. Even faster door-to-alteplase times and associated outcomes in acute ischemic stroke. J Stroke Cerebrovascular Dis. (2019) 28:104329. doi: 10.1016/j.jstrokecerebrovasdis.2019.104329

69. Kamal N, Jeerakathil T, Mrklas K, Smith EE, Mann B, Valaire S, et al. Improving door-to-needle times in the treatment of acute ischemic stroke across a Canadian Province: methodology. Crit Pathways Cardiol. (2019) 18:51-6. doi: 10.1097/HPC.0000000000000173

70. Burns JD, Rindler RS, Carr C, Lau H, Cervantes-Arslanian AM, GreenLaRoche DM, et al. Delay in diagnosis of basilar artery stroke. Neurocritical Care. (2016) 24:172-9. doi: 10.1007/s12028-015-0211-0

71. Kim JS. tPA Helpers in the treatment of acute ischemic stroke: are they ready for clinical use? J Stroke. (2019) 21:160-74. doi: 10.5853/jos.2019.00584

72. Olivato S, Nizzoli S, Cavazzuti M, Casoni F, Nichelli PF, Zini A. e-NIHSS: an expanded national institutes of health stroke scale weighted for anterior and 
posterior circulation strokes. J Stroke Cerebrovascular Dis. (2016) 25:295357. doi: 10.1016/j.jstrokecerebrovasdis.2016.08.011

73. Abzhandadze T, Reinholdsson M, Sunnerhagen SK. NIHSS is not enough for cognitive screening in acute stroke: a cross-sectional, retrospective study. $S c i$ Rep. (2020) 10:534. doi: 10.1038/s41598-019-57316-8

74. Lo EH, Matsumoto K, Pierce AR, Garrido L, Luttinger D. Pharmacologic reversal of acute changes in diffusion-weighted magnetic resonance imaging in focal cerebral Ischemia. J Cereb Blood Flow Metabol. (1994) 14:597-603. doi: $10.1038 / \mathrm{jcbfm} .1994 .74$

75. Schlaug G, Benfield A, Baird AE, Siewert B, Lövblad KO, Parker RA, et al. The ischemic penumbra. Operationally Defined Diffus Perf MRI. (1999) 53:1528. doi: 10.1212/WNL.53.7.1528

76. Kidwell CS, Alger JR, Saver LJ. Beyond mismatch: evolving paradigms in imaging the ischemic penumbra with multimodal magnetic resonance imaging. Stroke. (2003) 34:2729-35. doi: 10.1161/01.STR.0000097608.38779.CC

77. Nagaraja N, Forder JR, Warach S, Merino GJ. Reversible diffusion-weighted imaging lesions in acute ischemic stroke. A Syst Rev. (2020) 94:571-87. doi: 10.1212/WNL.0000000000009173

78. Heit JJ, Zaharchuk G, Wintermark M. Advanced neuroimaging of acute ischemic stroke: penumbra and collateral assessment. Neuroimag Clin North Am. (2018) 28:585-97. doi: 10.1016/j.nic.2018.06.004

79. Menon BK. Neuroimaging in acute stroke. Continuum. (2020) 26:287-309. doi: 10.1212/CON.0000000000000839

80. d. Peña Borlongan C, Shen G, Davis W. Strategies to extend thrombolytic time window for ischemic stroke treatment: an unmet clinical need. J Stroke. (2017) 19:50-60. doi: 10.5853/jos.2016.01515

81. Knecht T, Borlongan C, Dela Pena I. Combination therapy for ischemic stroke: novel approaches to lengthen therapeutic window of tissue plasminogen activator. Brain Circulat. (2018) 4:99-108. doi: 10.4103/bc.bc_21_18

82. Borlongan CV. Concise review: stem cell therapy for stroke patients: are we there yet? Stem Cells Transl Med. (2019) 8:983-8. doi: 10.1002/sctm.19-0076

83. Prabhakaran S, Ruff I, Bernstein AR. Acute stroke intervention: a systematic review. JAMA. (2015) 313:1451-62. doi: 10.1001/jama.2015.3058

84. Vanacker P, Lambrou D, Eskandari A, Ntaios G, Cras P, Maeder P, et al. Michel: improving the prediction of spontaneous and post-thrombolytic recanalization in ischemic stroke patients. J Stroke Cerebrovascul Dis. (2015) 24:1781-6. doi: 10.1016/j.jstrokecerebrovasdis.2015.04.002

85. Bacigaluppi M, Semerano A, Gullotta GS, Strambo D. Insights from thrombi retrieved in stroke due to large vessel occlusion. J Cereb Blood Flow Metabol. (2019) 39:1433-51. doi: 10.1177/0271678X19856131

86. Rui-Gang X, Robert AS. Insights into the composition of stroke thrombi: heterogeneity and distinct clot areas impact treatment. Haematologica. (2020) 105:257-9. doi: 10.3324/haematol.2019.238816

87. Qureshi AI, Qureshi MH, Lobanova I, Bashir A, Khan AA, Bologna SM, et al. Histopathological characteristics of IV recombinant tissue plasminogen -resistant thrombi in patients with acute ischemic stroke. $J$ Vascular Int Neurol. (2016) 8:38-45. doi: 10.1016/j.jstrokecerebrovasdis.2018.09.041

88. Wohner N, Sotonyi P, Machovich R, Szabo L, Tenekedjiev K, Silva MM, et al. Lytic resistance of fibrin containing red blood cells. Arteriosclerosis Thrombosis Vascular Biol. (2011) 31:2306-13. doi: 10.1161/ATVBAHA.111.229088

89. Jang IK, Gold HK, Ziskind AA, Fallon JT, Holt RE, Leinbach RC, et al. Differential sensitivity of erythrocyte-rich and platelet-rich arterial thrombi to lysis with recombinant tissue-type plasminogen activator. A possible explanation for resistance to coronary thrombolysis. Circulation. (1989) 79:920-8. doi: 10.1161/01.CIR.79.4.920

90. Lizarrondo SM, Gakuba C, Herbig BA, Repessé Y, Ali C, Denis CV, et al. Potent thrombolytic effect of Acetylcysteine on Arterial Thrombi. Circulation. (2017) 136:646-60. doi: 10.1161/CIRCULATIONAHA.117.027290

91. Denorme F, Langhauser F, Desender L, Vandenbulcke A, Rottensteiner $\mathrm{H}$, Plaimauer B, et al. ADAMTS13-mediated thrombolysis of t-PAresistant occlusions in ischemic stroke in mice. Blood. (2016) 127:2337-45. doi: 10.1182/blood-2015-08-662650
92. Ducroux C, Di Meglio L, Loyau S, Delbosc S, Boisseau W, Deschildre $\mathrm{C}$, et al. Thrombus neutrophil extracellular traps content impair tPAinduced thrombolysis in acute ischemic stroke. Stroke. (2018) 49:754-57. doi: 10.1161/STROKEAHA.117.019896

93. Meyer SFD, Suidan GL, Fuchs TA, Monestier MD, Wagner D. Extracellular chromatin is an important mediator of ischemic stroke in mice. Arterioscler Thrombosis Vascul Biol. (2012) 32:1884-91. doi: 10.1161/ATVBAHA.112.250993

94. Laridan E, Denorme F, Desender L, Francois O, Andersson T, Deckmyn $\mathrm{H}$, et al. Neutrophil extracellular traps in ischemic stroke thrombi. Annals Neurol. (2017) 82:223-32. doi: 10.1002/ana.24993

95. Meretoja A, Keshtkaran M, Saver JL, Tatlisumak T, Parsons MW, Kaste M, et al. Stroke thrombolysis. Stroke. (2014) 45:1053-8. doi: 10.1161/STROKEAHA.113.002910

96. Benedict CR, Refino CJ, Keyt BA, Pakala R, Paoni NF, Thomas GR, et al. New variant of human tissue plasminogen activator (TPA) with enhanced efficacy and lower incidence of bleeding compared with recombinant human TP. Circulation. (1995) 92:3032-40. doi: 10.1161/01.CIR.92.1 0.3032

97. Liberatore GT, Samson A, Bladin C, Schleuning WD, Medcalf LR. Vampire bat salivary plasminogen activator (desmoteplase): a unique fibrinolytic enzyme that does not promote neurodegeneration. Stroke. (2003) 34:537-43. doi: $10.1161 / 01 . S T R .0000049764 .49162 .76$

98. Röther J, Ford GA, Thijs VN. Thrombolytics in acute ischaemic stroke: historical perspective and future opportunities. Cereb Dis. (2013) 35:313-9. doi: $10.1159 / 000348705$

99. Parsons MW, Miteff F, Bateman GA, Spratt N, Loiselle A, Attia J, et al. Acute ischemic stroke: imaging-guided tenecteplase treatment in an extended time window. Neurology. (2009) 72:915-21. doi: 10.1212/01.wnl.0000344168.05315.9d

100. Parsons M, Spratt N, Bivard A, Campbell B, Chung K, Miteff F, et al. A randomized trial of tenecteplase versus alteplase for acute ischemic stroke. N Engl J Med. (2012) 366:1099-107. doi: 10.1056/NEJMoa1109842

101. Warach SJ, Dula AN, Milling JT. Tenecteplase thrombolysis for acute ischemic stroke. Stroke. (2020) 51:3440-51. doi: 10.1161/STROKEAHA.120.029749

102. Kratzschmar J, Haendler B, Langer G, Boidol W, Bringmann P, Alagon A, et al. The plasminogen activator family from the salivary gland of the vampire bat Desmodus rotundus: cloning and expression. Gene. (1991) 105:229-37. doi: 10.1016/0378-1119(91)90155-5

103. Li X, Ling L, Li CQ. Efficacy and safety of desmoteplase in acute ischemic stroke patients: a systematic review and meta-analysis. Medicine. (2017) 96:e6667. doi: 10.1097/MD.0000000000006667

104. Elmaraezy A, Abushouk AI, Saad S, Eltoomy M, Mahmoud O, Hassan HM, et al. Desmoteplase for acute ischemic stroke: a systematic review and metaanalysis of randomized controlled trials. CNS Neurol Disord Drug Targets. (2017) 16:789-99. doi: 10.2174/1871527315666161213110104

105. Fonarow GC, Zhao X, Smith EE, Saver JL, Reeves MJ, Bhatt DL, et al. Doorto-needle times for tissue plasminogen activator administration and clinical outcomes in acute ischemic stroke before and after a quality improvement initiative. JAMA. (2014) 311:1632-40. doi: 10.1001/jama.2014.3203

106. Dong Q, Dong Y, Liu L, Xu A, Zhang Y, Zheng H, et al. The Chinese Stroke Association scientific statement: intravenous thrombolysis in acute ischaemic stroke. Stroke Vascular Neurol. (2017) 2:147-59. doi: 10.1136/svn-2017-000074

Conflict of Interest: The authors declare that the research was conducted in the absence of any commercial or financial relationships that could be construed as a potential conflict of interest.

Copyright $\odot 2021$ Pan and Shi. This is an open-access article distributed under the terms of the Creative Commons Attribution License (CC BY). The use, distribution or reproduction in other forums is permitted, provided the original author(s) and the copyright owner(s) are credited and that the original publication in this journal is cited, in accordance with accepted academic practice. No use, distribution or reproduction is permitted which does not comply with these terms. 